\title{
Tendency of Thai High School Students' Emotional Stability before and During the COVID-19 Pandemic and Its Factors
}

\author{
Chutikan Saithasao $^{1}$, Chanokprattana Panyasuk ${ }^{2}$ \\ ${ }^{1}$ Amatyakul School, ${ }^{2}$ Triamudom Suksa School, Bangkok, Thailand \\ Corresponding Author: Chutikan Saithasao
}

\begin{abstract}
The World Health Organization (WHO) declared the COVID-19 outbreak to be an international public health emergency. Various situations affected global citizens physically and mentally. Focusing on high school students, we began collecting data via online questionnaires between May and July 2020, 145 valid answers in total. Perth Emotional Regulation Competency Inventory (PERCI) was used to assess emotional stability. We then statistically analyzed the data using Spearman's correlation coefficient between each factor. The data showed that emotional stability was reduced during the coronavirus situation. In addition, Economic status is an important factor affecting the tendency of emotional stability $(\mathrm{p}<0.01)$ due to the global economic crisis. The only variable showing slightly negative correlation was health. This was expected because over $60 \%$ of the participants had no infected acquaintances. Health concerns therefore played an inconspicuous role in emotional stability. The volatility of emotion could be a source of mental breakdowns and disastrous events in the future if people do not have the proper awareness.
\end{abstract}

Keywords: Emotional stability, COVID-19, High school students, Psychological impact, Mental health, Public health

\section{INTRODUCTION}

The COVID-19 pandemic is like an unexpected nightmare that no one ever imagined. Everything happened out of the blue. According to the World Health Organization (WHO), COVID-19, which stands for Coronavirus Disease 2019, is an infectious disease caused by a newly discovered strain of coronavirus. Most people containing COVID-19 will have respiratory problems. When an infected person coughs or sneezes, the virus spreads itself along with saliva or snot to reach its next target. In general, the virus can stay airborne for hours or stay on clothing for days. ${ }^{[1]}$ That is why uninfected people can infect those around them after going to a high-risk place or meeting an infected one.

Spreading all over the world, the disease has continued for more than a year and has changed people's lifestyles, such as social distancing measures and temporary closures of certain businesses. Schools have also offered online learning instead of traditional onsite learning to reduce the risk of spreading the disease. However, different approaches to learning and everyday life cause a great effect on mental health. ${ }^{[2]}$ There was a research finding that 71 percent of US university students have experienced increased stress during the COVID-19 pandemic due to multiple factors, for example, students' health and their loved ones, low sleep quality, fewer interactions with others, etc. ${ }^{[3]}$ Person's emotional state was illustrated to be significantly associated with a tendency toward emotional stability. ${ }^{[4,5]}$ Moreover, low emotional stability may lead to depression or more serious incidents in the future. ${ }^{[6]}$

Even now, plenty of vaccines are being developed to mitigate the damage 
from more infected people. It still does not seem to be enough to overcome this nightmare. This is evident from the rising number of infections. Keep in mind that human beings are self-developed, so are viruses. COVID-19 is thus able to mutate to survive the vaccine ${ }^{[7]}$ and continue to inflict endless fear on humans. That means our lives still have to continue in the situation that creates emotional volatility without knowing the end. This study was therefore carried out to examine the tendency of emotional stability among high school students from a school in Thailand, comparing emotional regulations before and during the COVID-19 outbreak. We hope that this study will lead to further study and be able to raise awareness in people about their changes and the following consequences to prevent it before it becomes a silent threat that infiltrates people's minds without them realizing it.

\section{MATERIALS \& METHODS}

We conducted the survey under 3 hypotheses:

(i) Health, social relationships, economic status, education, and others affected emotional stability before the COVID-19 pandemic.

(ii) Health, social relationships, economic status, education, and others affected emotional stability during the COVID-19 pandemic.

(iii) Emotional stability during the COVID19 pandemic scores are less than emotional stability before the COVID-19 pandemic scores.

Having 212 high-school students (Grade 10, Grade 11, Grade 12), regardless of gender, as a sample group, the questionnaire was developed and verified. Each item got an Item-Objective Congruence Index rating $(-1,0,1)$ more than 0.5 from the professors. We then collected data as an online survey by using Google Forms. The form consists of 4 sections:
1) Personal information: asked general questions about a grade, gender, and participants' COVID-19 situation, totally four questions. This section was used to examine their background.

2) Perth Emotional Regulation Competency Inventory (PERCI): the ten-item question created to measure the emotional stability of the participants before COVID-19 pandemic, using 5 scales for estimation ( 1 = strongly agree, $2=$ more agree, $3=$ agree, $4=$ less agree, $5=$ strongly disagree).

3) Perth Emotional Regulation Competency Inventory (PERCI): had all the same questions as the previous part, on the other hand, meant to determine the emotional stability after the COVID-19 pandemic.

4) The factors that affect Emotional stability: was a multiple-choice question, the participants could choose more than one factor depending on their opinion.

Finally, we put the data into the SPSS program for analysts into Cronbach's alpha and Spearman rank correlation (rho), under the formula $\rho=1-\frac{6 \sum d_{i}^{a}}{n\left[\left(n x^{2}-1\right)\right.} ; n$ is the number of observation, di is the difference between the 2 ranks of each observation.

\section{RESULT}

In this study, data were collected from 26 males, 97 females and 22 LGBTQ+. Data information is shown in table 1. Students in grade 12 mostly participate in this study during May to July 2021. Female students in all grades were informed (non) infected acquaintances that are better than males and LGBTQ+.

The Frequency table between infected and participants in different relationships such as family, cousins, peers, lovers, acquaintances, and others is shown in the table below.

Table 2 indicates that the emotional stability scores before COVID-19 pandemic (33.33) are slightly higher than the scores during COVID-19 pandemic (32.9). 
Chutikan Saithasao et.al. Tendency of Thai High School students' emotional stability before and during the COVID-19 pandemic and its factors

Table 1: Personal information

\begin{tabular}{|c|c|c|c|c|c|}
\hline & \multicolumn{3}{|c|}{ Gender } \\
\hline & & & Male & Female & LGBTQ+ \\
\hline & \multirow{3}{*}{ Class } & Grade 10 & $14 \%$ & $77 \%$ & $9 \%$ \\
\hline & & Grade 11 & $23 \%$ & $72 \%$ & $5 \%$ \\
\hline & & Grade 12 & $26 \%$ & $61 \%$ & $23 \%$ \\
\hline & \multirow[t]{3}{*}{ Infected acquaintance } & Grade 10 & $9 \%$ & $83 \%$ & $8 \%$ \\
\hline & & Grade 11 & $38 \%$ & $54 \%$ & $8 \%$ \\
\hline & & Grade 12 & $11 \%$ & $58 \%$ & $31 \%$ \\
\hline & \multirow[t]{3}{*}{ Non-infected acquaintance } & Grade 10 & $20 \%$ & $70 \%$ & $10 \%$ \\
\hline & & Grade 11 & $17 \%$ & $80 \%$ & $3 \%$ \\
\hline & & Grade 12 & $19 \%$ & $63 \%$ & $18 \%$ \\
\hline \multirow{18}{*}{$\begin{array}{l}\text { Frequency table between } \\
\text { infected and participants }\end{array}$} & \multirow[t]{3}{*}{ Family } & Grade 10 & $100 \%$ & $0 \%$ & $0 \%$ \\
\hline & & Grade 11 & $0 \%$ & $0 \%$ & $0 \%$ \\
\hline & & Grade 12 & $0 \%$ & $0 \%$ & $0 \%$ \\
\hline & \multirow[t]{3}{*}{ Cousins } & Grade 10 & $0 \%$ & $100 \%$ & $0 \%$ \\
\hline & & Grade 11 & $50 \%$ & $50 \%$ & $0 \%$ \\
\hline & & Grade 12 & $17 \%$ & $33 \%$ & $50 \%$ \\
\hline & \multirow[t]{3}{*}{ Peers } & Grade 10 & $0 \%$ & $100 \%$ & $0 \%$ \\
\hline & & Grade 11 & $0 \%$ & $100 \%$ & $0 \%$ \\
\hline & & Grade 12 & $13 \%$ & $63 \%$ & $25 \%$ \\
\hline & \multirow[t]{3}{*}{ Lovers } & Grade 10 & $0 \%$ & $100 \%$ & $0 \%$ \\
\hline & & Grade 11 & $0 \%$ & $0 \%$ & $0 \%$ \\
\hline & & Grade 12 & $0 \%$ & $0 \%$ & $0 \%$ \\
\hline & \multirow[t]{3}{*}{ Acquaintances } & Grade 10 & $0 \%$ & $100 \%$ & $0 \%$ \\
\hline & & Grade 11 & $50 \%$ & $38 \%$ & $13 \%$ \\
\hline & & Grade 12 & $10 \%$ & $70 \%$ & $20 \%$ \\
\hline & \multirow[t]{3}{*}{ Others } & Grade 10 & $0 \%$ & $0 \%$ & $100 \%$ \\
\hline & & Grade 11 & $0 \%$ & $0 \%$ & $0 \%$ \\
\hline & & Grade 12 & $0 \%$ & $100 \%$ & $0 \%$ \\
\hline
\end{tabular}

Table 2: means and standard deviation of emotional stability scores before and during COVID-19 pandemic

\begin{tabular}{|c|c|c|c|c|c|}
\hline \multicolumn{2}{|c|}{ Emotional stability scores } & Mean & N & Std. Deviation & Std. Error Mean \\
\hline \multirow{2}{*}{ Pair 1 } & Before COVID-19 pandemic & 33.33 & 145 & 7.886 & 0.655 \\
\cline { 2 - 6 } & During COVID-19 pandemic & 32.9 & 145 & 8.818 & 0.732 \\
\hline
\end{tabular}

\begin{tabular}{|c|c|c|c|c|}
\hline \multicolumn{2}{|c|}{ Emotional stability scores } & 95\% Confidence Interval of the Difference & \\
\hline & & Lower & Upper & Sig (2-tailed) \\
\hline Pair 1 & Before COVID-19 pandemic - & -.341 & 1.210 & .270 \\
\hline & During COVID-19 pandemic & & & \\
\hline
\end{tabular}

Table 3: Correlation coefficient from Spearman rank correlation method among emotional stability score before COVID-19 and factors affecting the score

\begin{tabular}{|c|c|c|c|c|c|}
\hline \multirow[t]{2}{*}{ Items } & \multicolumn{5}{|c|}{ Factors } \\
\hline & Health & Social relationship & Economic status & Education & others \\
\hline Emotional stability scores & -0.047 & 0.031 & $0.212 * *$ & 0.118 & -0.167 \\
\hline Health & & $0.239 * *$ & $0.434 * *$ & $0.226 * *$ & -0.107 \\
\hline Social relationship & & & $0.275^{* *} *$ & $0.221 *$ & -0.114 \\
\hline Economic status & & & & $0.246^{* *}$ & $-0.116^{*}$ \\
\hline Education & & & & & 0.154 \\
\hline
\end{tabular}

Table 4: Correlation coefficient from Spearman rank correlation method among emotional stability score during COVID-19 and factors affecting the score

\begin{tabular}{|l|c|c|c|c|c|}
\hline \multirow{2}{*}{ Items } & \multicolumn{4}{c|}{ Factors } \\
\cline { 2 - 6 } & Health & Social relationship & Economic status & Education & others \\
\hline Emotional stability scores & -0.026 & 0.002 & $0.299^{* *}$ & 0.044 & -0.111 \\
\hline Health & & $0.239^{* *}$ & $0.434^{* *}$ & $0.226^{* *}$ & -0.107 \\
\hline Social relationship & & & $0.275^{* *}$ & $0.221^{* *}$ & -0.144 \\
\hline Economic status & & & 0.246 & $-0.166^{*}$ \\
\hline Education & & & & -0.154 \\
\hline
\end{tabular}

Table 3 represents a moderately positive correlation between emotional stability scores and economic status $(\mathrm{r}=0.212 ; \quad \mathrm{p}$-value $<0.01)$ before the pandemic. Similarly, education, health, social relationship and economic status have moderately positive relationships $(0.226$ to
$0.434 ; \mathrm{p}<0.01)$. It indicated that before the COVID-19 pandemic if emotional stability scores increase, the economic status will be improved. Education, health, social relationship and economic status have significantly synergistic interaction. 
Table 4 represents a moderately positive correlation between emotional stability score and economic status $(\mathrm{r}=0.3$; $\mathrm{p}$-value<0.01) during the pandemic. Similarly, education, health, social relationship and economic status have moderately positive relationships $(0.221$ to $0.434 ; \mathrm{p}<0.01)$. It indicated that during the COVID-19 pandemic if emotional stability scores increase, the economic status will be improved. It's similar to the results of the scores before COVID-19 situation. Associations among education, health, social relationship, and economic status are significantly optimistic.

\section{DISCUSSION}

Emotional stability refers to a continuous process of striving to increase emotional well-being both in terms of mind and personality. Emotional stability helps a person to develop an integrated and balanced awareness of life's problems. ${ }^{[8,9]}$ It is also a key contributor to a person's success. Emotional regulation can be affected by stress when it comes to difficult situations. Stability is not just the ability to adapt but also the ability to counteract with negative emotions that are the source of stress so that a person can effectively perform tasks. ${ }^{[10]}$

The results showed that three-fourths of the main variables were positively correlated with emotional stability, while health was negatively correlated. On the other hand, health, education, and social relationships had the Spearman's $\rho$ closer to 0 , while the correlation between economic status and emotional stability was evidently more positive. However, the correlation between the 4 variables is very strong ( $\mathrm{P}$ value is less than 0.01). It also demonstrated that the emotional stability level during the COVID-19 situation was lower than before the outbreak, suggesting that our hypothesis might be proved.

Money never slips out of being a crucial thing in life. It is an important factor that leads people to the opportunity to access things. It is therefore not surprising to find that financial status has a strongly positive correlation with emotional regulation competency before the COVID19 situation and even stronger during the pandemic. Certain businesses, especially tourism, have lately gone into liquidation due to the financial crisis. As a result, the unemployed population in Thailand has increased considerably in a short period. ${ }^{[11]}$ High school students definitely know the situation within their own families well. Family debt or parents' unemployment directly affects their lives. They might experience stress and anxiety which can develop into emotional instability. ${ }^{[12]}$

The high rate of academic competition has long stressed Thai students. However, some students have had decreased concentration in study materials due to external factors such as internet surfing and household chores their parents ask them to do. ${ }^{[13]}$ They felt motivated by neither lessons nor exams since the answer keys can be found in many sources. ${ }^{[14]}$ As if the role of academic performance in their minds has faded. In terms of social relationshipsdefined as Repetitive interactions with those around them that have a personal meaning for each, such as family, friends, neighbors, but does not include superficial encounters. ${ }^{[15]}$ Amid the epidemic of various strains of COVID-19 which spreads itself rapidly and is able to live in the air for more than 3 hours $^{[16]} 72$ hours attaching to clothes. $^{[1]}$ Going out, interacting with people, and coming back home has no difference from putting themselves and their loved ones at risk of infection. Some people, therefore, decided to follow the government's stay-at-home policy. Besides, although they are at home, they can still connect with others through social media, so it relieves much of a concern. ${ }^{[17]}$ These can be the explanation of the weaker correlation between emotional stability and education, as well as social relationships.

Out of 145 participants, $64.8 \%$ had no infected acquaintance. It is possible that they still think the 'virus thing' is distant. Even if they accidentally got infected, there 
would be plenty of medical units in charge of taking care of them. The ones who follow another popular method, home isolation, also access medication with help of aid organizations conveniently. Furthermore, care and encouragement from people around them help the patient's mind become stronger as well. ${ }^{[18]}$ As a result, health shows a slightly negative correlation with emotional stability.

The changes in emotional stability during the COVID-19 pandemic compared to before such a situation found in this research was consistent with the results of the Spanish general population mental health research, led by Rocío RodríguezRey. ${ }^{[19]}$ The economic impact was also the largest factor affecting the mental health of participants in both Rocío Rodríguez-Rey's study and this study.

\section{CONCLUSION}

The correlation scores of emotional stability and economic status was strong $(p<0.01)$ both before and during the COVID-19 pandemic. However, the emotional stability scores during COVID-19 pandemic are lower. The difference value of emotional stability scores between before the COVID-19 pandemic and during the COVID-19 pandemic are 0.270. This consequence compares emotions between normal and abnormal situations.

\section{Acknowledgement: None}

\section{Conflict of Interest: None}

\section{Source of Funding: None}

\section{Ethical Approval: Approved}

\section{REFERENCES}

1. DMU. Research shows coronavirus can survive on healthcare uniforms for three days. [Internet]. 2021. [updated 2021 Feb. 23; cited 2021 Aug. 16]. Available from https://www.dmu.ac.uk/aboutdmu/news/2021/february/research-showscoronavirus-can-survive-on-healthcareuniforms-for-three-days.aspx

2. Kento Tanaka, Masatoshi Tahara, Yuki Mashizume, Kayoko Takahashi. Effects of
Lifestyle Changes on the Mental Health of Healthcare Workers with Different Sense of Coherence Levels in the Era of COVID-19 Pandemic. Int J Environ Res Public Health. 2021; 18(6): 2801.

3. Son, C., Hegde, S., Smith, A., Wang, X., Sasangohar, F. Effects of COVID-19 on College Students' Mental Health in the United States: Interview Survey Study. Journal of Medical Internet Research. 2020; 22(9): e21279.

4. Ho, M. Y., Cheung, F. M., You, J., Kam, C., Zhang, X., Kliewer, W. The moderating role of emotional stability in the relationship between exposure to violence and anxiety and depression. Personality and Individual Differences. 2013; 55(6):634-639.

5. Wehner, C., Schils, T., Borghans, L. Personality and Mental Health: The Role and Substitution Effect of Emotional Stability and Conscientiousness. IZA Discussion Papers. 2016; No. 10337.

6. Angelo Compare, Cristina Zarbo, Edo Shonin, William Van Gordon, Chiara Marconi. Emotional Regulation and Depression: A Potential Mediator between Heart and Mind. Cardiovasc Psychiatry Neurol. 2014; 2014: 324374.

7. Noh, J.Y., Jeong, H.W., Shin, EC. SARSCoV-2 mutations, vaccines, and immunity: implication of variants of concern. Sig Transduct Target Ther. 2021; 6, 203.

8. Smithson WB. Psychological adjustment: Current concepts and applications. New York: McGraw Hill Book Company. 1974.

9. M. Chaturvedi, R. Chander. Development of emotional stability scale. Ind Psychiatry J. 2010; 19(1): 37-40.

10. Serebryakova, T. A., Morozova, L. B., Kochneva, E. M., Zharova, D. V., Kostyleva, E. A., Kolarkova, O. G. Emotional Stability as a Condition of Students' Adaptation to Studying in a Higher Educational Institution. International Journal of Environmental \& Science Education. 2016; 11(15), 7486-7494.

11. S. Pongsakornrungsilp, P. Pongsakornrungsilp, V. Kumar, B. Maswongssa. The Art of Survival: Tourism Businesses in Thailand Recovering from COVID-19 through Brand Management. MDPI. 2021; 13, 6690.

12. Shahla ALI AHMED, Yağmur ÇERKEZ. The Impact of Anxiety, Depression, and Stress on Emotional Stability among the 
University Students from the view of educational aspects. Propósitos y Representaciones. 2020; Dic. 2020, Vol. 8, $\mathrm{N}^{\circ} 3$.

13. Sri Gustiani. Students' Motivation in Online Learning during COVID-19 Pandemic Era: A Case Study. Holistics Journals. 2020; Volume 12, Number 2, p-ISSN 2085-4021 | e-ISSN 2657-1897.

14. Amy Lathrop. Impact of Student Motivation in Online Learning Activities. Theses, Dissertations, and Student Research in Agronomy and Horticulture. 2021; 24.

15. August K.J., Rook K.S. Social Relationships. In: Gellman M.D., Turner J.R. (eds) Encyclopedia of Behavioral Medicine. Springer, New York, NY. 2013.

16. Thomas Bourdrel, Isabella AnnesiMaesano, Barrak Alahmad, Cara N. Maesano, Marie-Abèle Bind. The impact of outdoor air pollution on COVID-19: a review of evidence from in vitro, animal, and human studies. European Respiratory Review. 2021; 30: 200242.

17. Jaana Juvonen, Hannah L. Schacter, Leah M. Lessard. Connecting electronically with friends to cope with isolation during COVID-19 pandemic. Journal of Social and
Personal Relationships. 2021; Volume: 38 issue: 6, page(s): 1782-1799.

18. T. Rahimi, N. Dastyar, F. Rafati. Experiences of family caregivers of patients with COVID-19. BMC Fam Pract. 2021; 22, 137.

19. R. Rodríguez-Rey, H. Garrido-Hernansaiz, S. Collado. Psychological Impact and Associated Factors During the Initial Stage of the Coronavirus (COVID-19) Pandemic Among the General Population in Spain. Frontiers in Psychology. 2020.

20. Preece, D. A., Becerra, R., Robinson, K., Dandy, J., Allan, A. Measuring emotion regulation ability across negative and positive emotions: The Perth Emotion Regulation Competency Inventory (PERCI). Personality and Individual Differences. 2018; 135, 229-241.

How to cite this article: Saithasao C, Panyasuk C. Tendency of Thai High School students' emotional stability before and during the COVID-19 pandemic and its factors. International Journal of Science \& Healthcare Research. 2021; 6(3): 339-344. DOI: https:// doi.org/10.52403/ijshr.20210758 